\title{
Evaluating the role of Trade Unions and Civil Society Organisations in Supporting Graduate Educated Disabled Workers
}

\section{Laura William, University of Greenwich}

Ian Cunningham, University of Strathclyde

This study explores the perceptions of disabled graduates regarding the effectiveness of employment-related advice and support provided by trade unions and civil society organisations (CSOs). The paper reveals distinct areas of expertise, with union impact largely based in the workplace, as disabled graduates indicate limited knowledge of collectivism or broader union national disability campaigns. CSOs engage with disabled graduates across a broader range of themes, including access to the labour market and disability-related policy, with some indirect influence on workplace issues, and meet all four of Bellamere's criteria for an industrial relations actor. In the face of concerns with the effectiveness of these representative institutions, the study identifies some conditions that may favour coalitions to support disabled workers, drawing on union and CSO's distinct and overlapping areas of expertise.

\section{Key words}

Disability, Civil Society Organisations, Trade Unions, Vulnerable Workers, Workplace Representation.

\section{Introduction}

Despite improved HR practices there is ongoing discrimination and distinct disadvantage experienced by disabled people compared to their non-disabled counterparts (Richards and Sang, 2016). There is a 34 percent employment gap between the employment rate of disabled and non-disabled people (DWP, 2016) and they are more likely to be engaged in precarious work (Office for Disability Issues, 2014; Wilton, 2006). Moreover, 19 percent of claimants at Employment Tribunals are disabled compared to eleven percent of the general working population (Harding et al., 2014): indicating a greater likelihood among disabled people to need to make a claim at an Employment Tribunal. 
Given the employment disadvantage faced by disabled workers, this raises questions concerning where they turn for representation when facing workplace discrimination, and whether institutions such as unions and other actors are effective. Existing evidence builds a picture of a vulnerable group of workers where only a minority have access to collective representation. The heterogeneity of the disabled community means that often a collective identity is not shared, making unionisation difficult (Foster and Fosh, 2010). Nevertheless, disabled workers (where unionisation stands at 27.3\%) are more likely to be trade union members than non-disabled workers (22.9\%) (Department for Business Innovation and Skills, 2016). There are also higher unionisation levels in the public sector where disabled employees are concentrated (ONS, 2017). Discrimination remains constant, however, where unionised organisations do not have better outcomes in terms of disability policies (Hoque and Noon, 2004).

This article explores disabled people's (graduates) perceptions of unionised forms of representation compared to other employment relations actors (in this case CSOs) when seeking support for employment-related problems. The reasons for studying unions and CSOs together stems from several concerns including: questions over the adequacy of traditional declining union forms of representation for vulnerable groups such as disabled employees; in the context of this decline, the emergence of CSOs as new actors fulfilling representative functions; and the growth in studies exploring the involvement and possible complementarity of these institutions in the working lives of vulnerable workers (Van Wanrooy, 2013; Colgan and Ledwith, 2002; Heery et al., 2012; Mustchin, 2014). The study explores several research questions: 1. Why do disabled graduates turn to external organisations for support in employment-related matters? 2. What role do unions and CSOs play in supporting disabled graduates in employment related matters and what are the perceptions of disabled people concerning the effectiveness of these representative institutions in dealing with their problems? In particular are CSOs taking on the role of an industrial relations actor in the same way as unions?

This research will determine the nature of the support provided by the representative organisations. In doing so, this paper extends understanding and knowledge of new 
employment relations actors and their significance in representing the interests of a disadvantaged, minority group. This topic is pertinent given the established disadvantage of disabled people in the labour market and new forms of representation which challenge Dunlop's (1993) three party model of employment actors and considers Bellemare's (2000) concept of the attributes of an industrial relations actor. The paper begins by providing an exploration of the role and effectiveness of trade union approaches to achieving equality in the workplace. This is followed by an overview of the characteristics of an employment relations actor, and how CSOs match these features with regard to their roles in representation in equality issues. Following on the methods, findings and discussion are presented.

\section{Trade unions and equality}

Unions mediate equality in two ways; firstly through ensuring collective bargaining has an equality dimension and secondly supporting members to take legal action (Conley, 2014). There are, however, debates about how effectively unions fulfil these functions. Some studies show that equality rights are more likely to be secured in workplaces where unions are present (Bacon and Hoque, 2012) and unions are the only workplace actors who can ensure disability issues are addressed on organisation-wide agendas (Foster and Fosh, 2010). Union structures can affect the success of such equality agendas; effective equality bargaining is facilitated by centralized bargaining systems; high bargaining coverage and strong union density (Blaschke, 2015). Democratic structures that allow disadvantaged groups representation in the senior union ranks are also important (Blascke, 2015; Milner and Gregory, 2014).

Simultaneously, union density, the scope of bargaining and centralised negotiations have significantly declined in the UK. Such decline diminishes the potential for collective efforts on equality to impact the working lives of disabled workers (Van Wanrooy et al., 2013). In particular, unions are viewed as inaccessible to vulnerable groups such as those outside the conventional employment relationship (Kolins Given, 2007) which is a particular concern given the likelihood for disabled people to be in non-standard employment (Schur et al., 2009). Unions also struggle to fill this 'representation gap' due to a range of complex factors, including the changing workforce composition towards non-manual, private service work where many disabled people are located where unions are weak, and find it difficult to organise (Dolton and Makepeace, 2010). Subsequently, some of those in need of union assistance because of workplace discrimination will have no access to it. 
In addition, unions are accused of failing in their democratic purpose in representing the interests of a large proportion of their members from groups vulnerable to discrimination (Colgan and Ledwith, 2002). Unions have struggled to recognise and manage the different interests of members based on their social identity, e.g. gender and ethnicity (Kirton and Greene, 2015). Colling and Dickens (2001) found that collective bargaining agreements often formalised and extended tacit discrimination.

Unions have attempted to address these equality challenges, but their success has been uneven and patchy (Milner, 2017; Richards and Sang, 2016), focusing predominantly, although not exclusively, on gender (Milner, 2017). One method to promote inclusion is through equality representatives. Bacon and Hoque (2012) report that three fifths of equality representatives positively impacted employer disability practices. More specific to disabled workers is the role of Disability Champions, who are lay trade union representatives that encourage employers to improve disability policies and offer advice and support (Bacon and Hoque, 2015). Approximately $75 \%$ of Disability Champions reported a positive impact on at least one element of disability policy and practice (Bacon and Hoque, 2015). The impact of Disability Champions, however, was contingent on supportive voice mechanisms, direct access to employees, the Disability Champions' longevity and experience, and the amount of hours spent on the role (Bacon and Hoque, 2015).

Despite moves to include specialist representatives, problems remain - few union representatives feel that their equality efforts are supported by employers (Heery, 2006); disability law remains complex; the training of such representatives remains problematic (Foster and Fosh, 2010); for those in-post issues of time, resources and competing priorities undermine their efforts (Foster, 2015); and securing reasonable adjustments for disabled workers remains complex (Bacon and Hoque, 2015).

Another area of complexity for union representation, is the lack of a homogenous identity or a set of unified interests among disabled workers (Foster and Fosh, 2010). Randle and Hardy (2016), for example, noted that inequalities among disabled people are not experienced 
uniformly and are mediated by different production processes and organisational settings, as well as different types of impairment. Furthermore, disability is not necessarily static but changes over time, as is the case with progressive conditions (Doyle, 1995). For collective organisations, this requires some recognition of an individualistic orientation towards handling disability issues, while avoiding treating workers in an inconsistent and ad-hoc way. Keen to address a fragmented identity among disabled workers, the TUC has adopted, nationally, the social model of disability and developed appropriate training, campaigned to ensure the UK's Public Sector Equality Duty is complied with, and represented employees regarding mental health and access to sickness benefits (TUC, 2015; Bacon and Hoque, 2015).

\section{The role of other actors in securing equality outcomes}

According to Williams et al., (2011a) several factors have led to increased interest in the potential greater regulatory role of other representative bodies in securing equality outcomes for vulnerable groups. The first is CSO success at lobbying the state on issues relevant to workers such as the living wage (Kolins Givan, 2007). The second is the aforementioned decline in unions and the joint regulation of the employment relationship. Gaps in representation from unions lead to questions regarding the possibility of a greater role of other organisations such as CSOs in providing a voice for disabled people.

Dunlop (1993) proposed a systemic model of industrial relations systems comprising three actors; the state, employers and unions. Since this model's inception it has been developed to include newer employment relations actors in response to the growth of interest in the campaigning, advocacy, advisory and service institutions that have arisen alongside unions (Heery and Frege, 2006). In order to understand what type of organisation is an actor and to insert rigour to Dunlop's model, Bellemare (2000) proposes an analytical model of an industrial relations actor. This proposition is a more generic model of an actor based on structuration theory (Hickey, 2012). Bellemare (2000) proposes that an actor is an individual or institution that 'has the capability to make a difference in some tangible process or in the course of events' (2000:386). In order to determine if an institution is an actor in the employment relations field it needs to operate at three different levels; the workplace, organisation and state (Bellemare, 2000). Additionally, the actors' influence can be measured on two dimensions; instrumental and outcomes. Instrumental relates to the extent to which the actor is involved in the three aforementioned levels. Outcomes relates to the ability of the actor to achieve change through 
influencing other actors (Bellemare, 2000). An employment relations actor must engage in continuous action at all three levels (workplace, institutional and state) (Bellemare, 2000). To satisfy the outcome dimension, the actor must be able to reach its objectives or produce transformation in the employment relations arena. Bellemare (2000) promotes the empirical analysis of institutions to determine their status as an actor.

\section{CSOs as industrial relations actors}

A CSO refers to a broad range of organisations such as charities, faith organisations, voluntary associations, advocacy bodies, social movement agencies and other non-governmental bodies (Williams et al., 2011a). CSOs are characterised by their indirect worker representation outside the boundaries of an organisation (Williams et al., 2011b). Research shows workers usually engage with CSOs on the basis of social identity (Kolins Givan, 2007). Such social identity politics suggest CSOs would have a vested interest in equality based on a social justice rationale. In contrast, union membership is tied to class, the workplace and based on formal bureaucratic rules (Heery et al., 2012).

CSOs frequently take on equality and diversity representational roles (Williams et al., 2011a; 2011b). CSOs have positioned themselves as interpreters of legislation where they provide advice and guidance on legislative compliance in the equality arena (Williams et al., 2010) so making tangible differences in the organisation and workplace.

Civil society regulation has been successful at mitigating employment discrimination, enhancing work-life balance, embedding flexible working arrangements and improving the condition of vulnerable workers (Williams et al., 2011b). Kolins Givan (2007) reports nonbargaining organisations are better placed to represent political and legal interests of workers than contemporary unions due to greater political voice, so producing tangible results at the level of the state. There are examples of CSOs successfully filling Bellemare's (2000) criteria for their actions with migrant workers (Hopkins and Dawson, 2016). Such organisations cultivate a 'relational culture' where they focus on developing relationships between members and organisations which results in high levels of social commitment which contrasts with unions who have a service driven culture (Tapia, 2013). 
Heery et al. (2012) identified a bifurcated approach to how CSOs influence the employment environment; advising workers and secondly lobbying activity to influence state policy achieved through the compliance and deterrence approach. The compliance approach utilises education and persuasion while the deterrence approach relies on threats of sanctions to entice adherence to rules (Hood et al., 2001). Heery et al., (2004) report that CSOs spend a significant amount of their time trying to impact employment standards by indirectly influencing public policy and government, suggesting the compliance approach is most common. Williams et al., (2011b) report that CSOs also assimilate information to highlight and raise awareness of the 'desirability of regulation' and also take action on behalf of individuals; for example the Citizen's Advice Bureau (Williams et al., 2011a:52). This assimilation allows CSOs to provide expertise upon which government and employers can draw. Finally, CSOs disseminate information to help regulate the workplace, which raises awareness and influences key decision makers of wider concerns in the employment field and they act as a source of legitimacy when handling difficult aspects of business practice (Williams et al., 2010).

Some research indicates that CSOs are usually involved with vulnerable workers, such as the low paid (Tailby et al., 2011). With regard to disability, voluntary organisations support people with specific medical conditions and some provide workplace support (Foster and Fosh, 2010). The Royal National Institute for the Blind (RNIB), for example, mediates legislation by issuing codes of practice and supporting individuals who make claims. Foster and Fosh (2010) found that a significant proportion of disabled workers preferred to approach a voluntary organisation rather than a union for support and advice on disability issues in the workplace. Humphrey (2000) argues that impairment specific organisations are better placed than unions to understand the situation of disabled workers.

Freeman (2005) however, has called into question the ability of CSOs to benefit workers directly. Foster and Fosh (2010) report that voluntary, general and impairment specific organisations often campaign on narrowly defined issues relevant to their membership and are, therefore, of less use to disabled workers and they report unions are best placed to support disabled workers. 
While extant work focuses on unions and CSOs as independent organisations, a smaller body of work has considered the relationship between the two organisations. While Mustchin (2014) found that trade union and CSO alliances can provide specialist support for vulnerable workers usually in the 'common cause' format identified in Frege et al (2004). In contrast, Richards and Sang (2016) found that the collectivist ideology driving unions was at odds with the individualist approach taken by advocacy organisations, which hindered collaboration. Heery et al. (2012) conclude that CSOs and TU relationships are characterised by a complex set of relationships that display aspects of agreement, indifference and antagonism.

Turning from CSO/TU coalitions, this paper uses Heery et al., (2012) bifurcated approach to examine the role and perceived applicability of unions and CSOs with regard to one of their functions, advice giving to disabled employees.

\section{Methods}

The data are drawn from qualitative interviews with 31 disabled workers and five trade union and civil society representatives, collected between 2009 and 2011. The data was part of a wider research project that examined the labour market experiences of disabled graduates in regard to: recruitment and selection, the role of external agencies to support disabled graduates and benefits. The research used a life history method which examined individual representation for workplace issues.

A purposive opportunist sampling approach was used with advertisements placed in media channels such as 'Linked-In', impairment specific and general disability websites and the published disability press; each separate group proved very difficult to contact and engage. Initially, the disabled workers were interviewed, all of whom were graduates with a minimum of a Bachelor's degree and self-defined themselves as disabled. Current statistics show that working age disabled people are half as likely to have a degree than non-disabled people; $14.9 \%$ of disabled people hold a degree compared to $28.1 \%$ of non-disabled people (Office for Disability Issues, 2014). Despite this lower representation disabled graduates are pertinent to research given their dual identity. They are graduates and, therefore, sought after in the labour market (Brown et al., 2011), but simultaneously disadvantaged by their disability status (Lengnick-Hall et al., 2008). Over a quarter of jobs in the UK now require a degree, therefore, it is important to understand the employment experience of a group of workers who can fulfil this criteria (Coughlan, 2013), where securing graduate employment is particularly challenging 
for disabled graduates (Equality Challange Unit, 2014). While this sample is not representative it allows insight into the lived experience of a valuable group in society.

Semi-structured interviews created a rich study and eliciting personal narratives gave voice to the disabled workers. Interviews took a chronological approach to aid recall when discussing past events; how the person remembers the past can be the most important part of the story they will tell (Gusdorf, 1980). The research included a wide variety of participants to give context to the narratives of the graduates. While the graduates remained the focus of the research, incorporating additional employment actors added depth and breadth to the research.

Interviews lasted 90 minutes on average, were audio recorded, transcribed verbatim and subject to complete coding, by hand, for thematic analysis (Braun and Clarke, 2013). Initially deductive coding was used, where pre-set codes from the literature were used, such as type of organisation contacted, reason for contact. After these literature driven codes were complete, the data was revisited to ascertain the scope for inductive codes. It was at this point codes which were not anticipated at the start of the project were created such as 'trust relationship' and 'role of CSO education'. As new codes emerged, all previous transcripts were re-analysed using the new codes and finally codes were aggregated into themes. Conducting disability research involves vast ethical considerations, therefore, all data was stored confidentially and anonymised, informed consent was obtained and all data handling conformed to the Data Protection Act 1998.

The study focused on the advice giving arm of Heery et al's (2012) bifurcated approach. The paper focuses on unions and CSO as these were the organisations that the participants reported they approach for support. Comparing and contrasting these two important types of organisations develops an understanding of why these organisations are chosen and how effective they are from the perspective of the participant. Such participant-led data allows insights into the lived experience of disabled people. An in-depth review of trade union and CSO activities in the political lobbying arena has not been undertaken as the research focused on the lived experience of the disabled graduate seeking workplace support. Focusing only on workplace support allows the participant space to discuss their perspectives on the role and scope of various support organisations. Focusing on their actual perceptions of unions and CSOs, reveals the extent to which wider lobbying and persuasion tactics are understood and processed by disabled graduates. 


\section{Findings}

The findings first examine the role and scope of unions and then CSOs.

\section{The role of unions}

Seven of the 31 disabled graduates had contact with unions, four of whom were union members (see table 1).

\section{INSERT TABLE ONE HERE}

When participants were questioned why they were not union members, the reasons varied between a lack of knowledge, not being approached to join a union, their contractual status (temporary employment), questioning the relevance of membership and a general negative image of unions. Several participants were working on fixed term contracts which deterred them from joining unions. Lisa reported that when she was on short term contracts '...it's never entered into the thing [work], it's a bit like pensions before you can start it is time to shut it down'. Lisa anticipated joining a union when she secured a permanent post. There was a general apathy towards unionisation, where it had not occurred to people to join as they felt the union would be unable to help them. With regard to the negative perceptions of unions, Joanna reported: 'I grew up with strikes in the 70s and the power cuts, so unions are bad!'

Despite the above attitudes, the remaining participants joined unions to seek protection in the face of personal health/disability discrimination issues (see table 1). In two instances union membership was sought to address issues around statutory sick leave (SSL) (Charles and Dot) and three joined for advice about potential discrimination (Hayley, Dot and Pam). Charles, a teacher, needed advice about SSL and discrimination. 
The data indicates a mixed response regarding the quality of union support for the above issues. Charles and Dot were both happy with the union support and believe their situation was taken more seriously because of union involvement. Pam and Hayley, in contrast, sought support for discrimination and were unhappy with the advice they were given. Participants who had negative experiences reported that their concerns were marginalised by wider union management issues and far down the list of priorities. For example, Pam:

'The union was helpful in the sense they came with me to the meeting and they did try to offer support at that point but the problem was the unions and the employer were at loggerheads over several issues to do with other areas and I think the relationship was just so bad that they actually saw my difficulty as quite minor compared to some of the other issues that were going on.'

On the other hand, when a participant contacted the union for straight forward advice the outcome was more positive. Charles, for example, received positive help regarding his statutory sick leave query.

There were three union members who were involved with the union as activists. David, Paul and Hayley were motivated to become involved with their unions to create change. David felt disabled employees were poorly represented in his union and joined to change the perception of disabled workers because he felt he had something to contribute.

I went back to the union committee and they seemed really interested because I think they had never had any disabled members on the committee. They are aware of the legislation and all the things they could be pushing for but it never had been in their face. And so they invited me to join the union committee.

Despite David's eagerness, he became disheartened when he realised the committee members paid scant attention to his work on disability equality and he felt they had little intention of implementing changes. David believes the union included him on the executive as part of efforts to give the impression of the inclusion of disadvantaged groups.

In terms of the frequency of contact with unions, apart from the participants who were activists within their unions, all participants only had one-off contact with their union, so it is not 
possible to ascertain whether repeated interactions would have established improved outcomes. As a result, it is suggested that unions helped with problems that fell within their usual area of workplace expertise but they were less helpful with issues that were more complex and of which they had less experience, such as disability discrimination. In terms, of explaining this poor response, an interview with a TU disability officer suggested a slow pace of change in his union.

'Looking back, we are still talking about the same kind of issues as 10 years ago, which you cannot say about any other area of workplace equality... But changes in the workplace, with some positive exceptions, have been slower than changes in the law.'

\section{The role of CSOS}

Eighteen participants reported they received help from general equality organisations, impairment specific organisations or general disability organisations, all of which fall within the Williams et al., (2011a) definition of a CSO. Data revealed that more contact was made with CSOs than unions. At the same time, data indicates this contact was because CSOs offered support in alternative fields.

The most commonly contacted type of CSOs was general disability organisations such as the Shaw Trust. Table two shows the most common reasons for contact with CSOs.

\section{INSERT TABLE TWO HERE}

The table shows that the most common reasons CSOs were contacted was for help to access the labour market. The sample included two CSO organisations which have dedicated graduate training schemes, one of which was created '...due to research done in 1999 by RNIB which aimed to find out the reason for blind and partially sighted people having high levels of unemployment.' In both cases the CSO interviewees reported the schemes were beneficial for graduates to give them experience and confidence in employment. One of the schemes reported $70 \%$ of participants secured full time work.

Several participants received support from CSOs that allowed them to progress their careers as they were finding it difficult to secure graduate employment. Support to enter work was vital 
in three participants' experiences. Claire, Joe and Lisa all took part in the SCOPE graduate training scheme ${ }^{1}$. Joe, in particular, was very positive about the influence of the scheme on his career. His placement led to a permanent job and feels that without the scheme he would not have found an employer 'to take a chance on me'. Despite not securing a permanent position Claire also had a positive experience where she could demonstrate she could hold down a job, with minimum reasonable adjustments and produce a very high standard of work. These examples show that some CSOs, especially the disability related CSOs have a direct influence in helping disabled graduates build careers.

CSOs were also contacted for advice about discrimination. For example, when Georgia faced discrimination, she sought help from a local law centre:

'the local community law centre is very good and has a disability law representative and they suggested that I would be able to take a case. They put me in touch with a lawyer... It was very helpful.'

This support was instrumental in Georgia making a successful case against her discriminators. In contrast, Pam contacted a CSO because she felt let down by her union. She felt unhappy with the support she received from the CSO, because of their lack of direct workplace influence:

I contacted CSO for advice but they had said to me, that I would have to take it through grievance procedure... before they would get involved. And I thought at the time, 'I can't do that.'

The variation in ability to address discrimination can be explained by the source of discrimination. In the case of Georgia she was discriminated by a housing association, and needed to bring a civil claim. In comparison, Pam's discrimination occurred in the workplace, where she had to follow a distinct procedure over which the CSO had little or no influence. In this instance it would appear that this lack of direct influence was key to the perceived failure of the CSO to support Pam.

\footnotetext{
${ }^{1}$ A graduate scheme that employs high calibre disabled people and sends them to host organisations for six month placements. The graduates carry out graduate roles in these organisations with support from SCOPE and SCOPE provides advice to the employers.
} 
Sophie's nursing colleagues refused to work with her when they discovered her impairment. Subsequently, Sophie used CSO resources to educate her colleagues about her epilepsy. Therefore, Sophie '...used the Epilepsy Society, got a load of leaflets from them, and I tried to educate the staff, so I had a group of staff that would work with me'. Further examples of workplace support include Lucy who wanted help funding a training course.

The disabled graduates did not report any impact of the CSO on the division or coordination of labour directly. However, the impact the CSO had on the ability for workers to continue to engage in employment, for example helping Joe secure reasonable adjustments, implies an organisational influence. SCOPE helped Joe understand what type of support he could receive from his employer and then gave the employer advice about how to implement such support. The relationship between SCOPE and Joe's employer led to the introduction of organisationwide agendas/policies and support to help disabled people, indicating an impact of CSOs at the organisation level.

Some participants used the CSO to become activists to lobby the state to promote equality. Amelia, Georgia and Joanna participated in CSOs because they wanted to make a difference, they saw their own identity reflected in that of the CSO and this fact attracted them to the CSO. Amelia undertook a central role with her impairment specific organisation. She enjoyed this role as it helped fill her time while she was unemployed. It was through working for the organisation she met her partner and it was an experience she enjoyed.

'So I got involved with the coalition from being a direct payments user and then I went onto the committee... I was a director with them for 6 years.'

Similarly Georgia was involved with her impairment specific organisation and finds her involvement interesting.

I I used to do very supportive campaigning like letter writing and supporting the people who go out and do the bigger things. Recently I have done some direct action campaigning: going to Downing Street and that sort of thing. It is exhausting but it is really interesting as well' 
Therefore, overall, participants reported CSOs were positive at mediating the work and the wider environment. Positive experiences ranged from being granted extra benefit payments because the Disability Living Allowance form had been filled out correctly, to feeling like they were accepted in an inclusive environment, as described by Joanna:

'...there was a stand for Disability Wales... this woman told me they were having a conference and why didn't I come along ... so I went along and I walked into a room of disabled people and for the first time in my life nobody stared at me!'

There were only two participants who were involved with both a CSO and a trade union, Pam and David. In both cases Pam and David were trade union members because they believed in collectivism and felt they could support and be supported by the union. However, when Pam and David sought support from the union, the union failed to help. Pam contacted the CSO as she felt the union had other priorities and was not willing to fight her case. David, despite being an active union member turned to the CSO for support claiming benefits because the union did not have the expertise to help.

\section{Comparison of the role of $T U$ and CSOS}

The data shows CSOs were contacted for general support about welfare issues, labour market problems and career support, in contrast unions were contacted about workplace issues. This pattern of contact reflects the relative expertise of the different organisations. Civil society organisations deal with a broader scope of issues, e.g. all issues that affect disabled people, while unions focus their efforts in the workplace

An explanatory factor to increased effectiveness and contact with CSOs is the amount of times they were accessed. Unions involved one-off contact, but, in contrast, CSOs were, in many cases, contacted numerous times, fulfilling the continuous criteria of Bellemare (2000). For example, Joe used a CSO to apply for jobs, the same CSO provided him with a graduate training scheme position and later helped him negotiate reasonable adjustments. This continued interaction established a trust relationship. The increased contact with CSOs reflects the greater visibility of CSOs to the sample. In contrast, the participants had less knowledge of unions and felt they were less relevant to their situation, therefore they were contacted less.

Many participants contacted CSOs who represented people with their specific impairment or general disabilities. As reported earlier, Joanna felt safe and Charles felt understood. Negative 
responses to impairments caused difficulties at work and it was these difficulties that prompted the participants to seek advice and support from external organisations with whom they identified. This data, suggests, therefore, that what draws people to contact a CSO is the ability for them to see their identity reflected in the CSO, which a more workplace focused organisation, such as a trade union, could be less likely to do.

The participants did not report any incidents of the CSOs using a medical model of disability. CSO support focused on removing societal barriers, such as stigma where Sophie used the Epilepsy Society information to educate her colleagues and Lisa who was provided with work experience to overcome the stigma that she was risky to employ. In a similar vein, the union interactions focused on removing societal barriers where participants were provided with advice to overcome stigma, the source of discrimination, such as Charles who used NUT to secure advice on SSL. These incidences point to both the unions and CSOs focusing on societal barriers as sources of discrimination for disabled people.

In contrast, the participants reported a difference in the underlying rationale in the CSOs and union. Unions were focused on collectivist purposes, for example Dot's union representative used this experience to foster wider union/employer agendas. Again, in contrast, and perhaps a function of their location outside the workplace, the CSO organisations were focused on individual solutions to problems with an absence of a collectivist agenda.

\section{Discussion}

This article investigated the perceptions of disabled graduates regarding the effectiveness of employment-related advice from trade unions and CSOs. The article contributes to debates focused on the role of traditional and new employment relations actors (Bellemare 2000; Heery et al., 2012). The article used Bellamere's (2000) four key criteria for establishing an industrial relations actor; continuity, outcomes, transformation and legitimacy.

The literature section identified union campaigning and influence on legislative and regulatory issues affecting disabled people (Bacon and Hoque, 2015). For our participants, however, union outcomes were mainly confined to the workplace level. This lack of participant awareness of union engagement at the policy level is unsurprising given unions were less visible to the graduates than CSOs; this lack of visibility possibly reflects the characteristics of 
the sample where young people in precarious work are least likely to be trade union members (Schur et al., 2009). The graduates in this study identified union interventions based around concerns such as SSL, which produced successful outcomes. Cases of discrimination were reportedly dealt with less successfully, however. The lack of success was blamed on the primacy of other workplace concerns and the lack of urgency in placing disability issues higher up the union agenda. These factors further add to our knowledge regarding the potential barriers facing union Disability Champions in the workplace (Bacon and Hoque, 2015). Moreover, these interactions between graduates and unions were largely one-off challenging Bellamere's (2000) continuity criteria. Yet, we have to be cautious about highlighting a failure by unions to engage in continuous relationships with disabled graduates, given the small size of the sample. Caution is also needed with regard to the assessing the perceptions of the effectiveness of union action among participants. The nature of the sample - graduates in precarious jobs, makes union impact at organisation level less likely, because of union lack of presence through recognition and membership. This finding does not mean, however, that unions are ineffective where they do have collective bargaining.

The evidence presented in this paper supports a growing body of work that agrees CSOs are a source of representation in the employment relationship (see: Heery et al., 2012; Osterman, 2006; Williams et al., 2011a, 2011b). The data revealed CSOs engaged with a broader range of issues. Disabled graduates perceived CSOs to be legitimate sources of knowledge and information, not only about legislation but also societal and medical issues. Interactions between CSOs and respondents were not isolated occurrences. CSOs were contacted numerous times, meeting Bellemare's (2000) continuity criteria. The outcomes from interactions with CSOs were also reportedly positive at organisational level, sometimes stopping the initial problem from escalating further. The ability of CSOs to transform the lives of the disabled graduates was apparent, with one respondent reporting they could not have worked without the intervention of the CSO.

The impact of CSOs on the workplace was less direct than unions. There are no instances where CSOs advised individuals to take action against employers. Rather, as in the case of Sophie, there was evidence of persuasion through using CSO materials to educate colleagues about discriminatory behaviour. This ability to indirectly influence the workplace through advice 
supports the work of Dickens (1989) who report CSOs as mediating agents because they help highlight the significance of law to the workplace (Heery et al, 2012).

These findings, in a similar vein to Heery et al., (2004), suggest the existence of indifference between the two representative institutions as CSOs and unions operate in distinct fields. CSOs were not replacing unions, but providing support and advice outside the expertise of traditional single channel representative bodies.

This is not to say, disabled graduates did not express preferences for one institution over the other. Foster and Fosh (2010) report that, despite impairment specific CSOs having a narrow focus that was unhelpful to workers, they were preferred over unions. This same preference for CSOs was expressed by our disabled graduates. In explaining such a view, this study, departs from some of the above research by contradicting the notion of narrowly focused CSOs, and highlighting how disabled people appreciated their broad advice. Moreover, in a similar vein to Williams et al., (2011a) and Piore and Stafford (2006), data reveals how attachments form between disabled workers and specific impairment-related CSOs, reflecting a trend of identity politics.

We add certain caveats with regard to the level of effectiveness and significance of CSOs. The data supports the finding that advocacy CSOs usually attract non-unionised and vulnerable workers (Heery et al., 2012). This raises the question regarding if there was the choice to approach unions, would CSOs be as attractive to disabled graduates? This is especially the case given data revealed that despite advances in helping disabled graduates, CSOs have little or no direct workplace influence (Kolin Givens, 2007).

A question remains regarding the potential for $\mathrm{CSO} /$ union alliances to help disabled workers. As seen in earlier work (Mustchin, 2014; Richards and Sang, 2016), this study found that an individualist agenda was favoured among CSOs compared to the collectivist one pursed by unions. Such conflicting agendas could complicate potential CSO/union alliances. At the same time, and in contrast to literature that suggests CSOs take a medical model approach to 
disability (Richards and Sang, 2016), this research found that like unions, CSOs embraced the social model. Moreover, unlike other union - CSO coalitions (see Mustchin, 2014), the struggle to gain rights at work for the disabled are not time limited. This last point suggests it could be time for each party to move from indifference to agreement (Heery, et al., 2012). Given the contribution of CSOs highlighted in this study, and positive examples of union activity from other studies (see Mustchin, 2014), possible synergies could include, for example, joint work on supply side labour market policies for disabled workers.

Further research is needed to establish the impact of CSO and union support to a wider group of disabled people (including non-graduates) in multiple workplace contexts to explore the generalisability of these results. In addition, research could also investigate the success, or otherwise, of coalitions between CSOs and unions.

\section{Conclusion}

This article addressed two key research questions: 1 . Why do disabled graduates turn to external organisations for support in employment-related matters? 2. What role do unions and CSOs play in supporting disabled graduates in employment - related issues and what are the perceptions of these vulnerable workers concerning the effectiveness of these representative institutions? The article contributes to knowledge in several key ways. Data highlights how disabled participants turned to external organisations for advice and support to challenge discrimination at work, but also other broader labour market issues.

The study illuminates the distinct areas in which unions and CSO operate most effectively in response to disabled graduate concerns. Despite, national campaigns, unions were perceived to largely provide support that was confined to workplace issues. In contrast, CSOs were contacted about return to work support, discrimination and non-workplace issues such as benefits, access to work and broader public policy concerns. The study, therefore, highlights unions struggling to be seen to be relevant to disabled graduates beyond the workplace. It further indicates how CSOs mediate the workplace indirectly, but make more direct impact on wider policy and labour market issues. Compared to their experiences with unions, disabled people appeared to engage in repeated interactions with the CSOs on a continuous basis, based 
on lack of awareness and availability of the former, and the expertise and broad scope of the latter. The study further shows CSOs can meet all four of Bellamere's (2000) criteria for an industrial relations actor. At the same time, the study finds common approaches to deal with disability as CSOs and unions draw on social model actions. Moving forward, unions and CSOs could investigate the feasibility of coalitions to support vulnerable workers drawing on each other's distinct and possible overlapping areas of expertise. Disabled employees could also be encouraged to look for support outside the traditional workplace/organisational boundaries.

\section{References}

Bacon N and Hoque K. (2012) The role and impact of trade union equality representatives in Britain. British Journal of Industrial Relations 50: 239-262.

Bacon N and Hoque K (2015) The influence of trade union Disability Champions on employer disability policy and practice. Human Resource Management Journal. 25;233-249 Bellemare G. (2000) End Users: Actors in the Industrial Relations System. British Journal of Industrial Relations 38: 383-405.

Blaschke S. (2015) Female representation in the decision-making structures of trade unions: The influences of sector, status and qualification. Journal of Industrial Relations 57: 726747.

Braun V and Clarke V. (2013) Sucessful Qualitative Research, London: Sage.

Brown P, Lauder H and Ashton D. (2011) The Global Auction Oxford: Oxford University Press.

Colgan F and Ledwith S. (2002) Gender and diversity: reshaping union democracy. Employee Relations 24: 167-189.

Colling T and Dickens L. (2001) Gender equality and the trade unions: a new basis for mobilisation? . In: Noon M and Ogbonna E (eds) Equality, Diversity and Disadvantage in Employment. Basingstoke: Palgrave, 136-155.

Conley H. (2014) Trade unions, equal pay and the law in the UK. Economic and Industrial Democracy 35: 309-323.

Coughlan S. (2013) More jobs for graduates than the unqualified in UK - study. Available at: http://www.bbc.co.uk/news/education-22268809. 
Department for Business Innovation and Skills. (2016) Trade Union Membership 2015. London: Department for Business, Innovation and Skills.

Dickens L. (1989) Women - a rediscovered resource? Industrial Relations Journal 20: 165175 .

Dolton P and Makepeace G. (2010) Public and Private Sector Labour Markets. In: Gregg P and Wadsworth J (eds) The Labour Market in Winter. Oxford: Oxford University Press. Doyle B. (1995) Disability Discrimination and Equal Opportunities: A Comparative Study of the Employment Rights of Disabled People, London: Mansell.

Dunlop JT. (1993) Industrial Relations Systems, Boston: Harvard Business School Press. DWP. (2016) Work, health and disability: improving lives. London: Department for Work and Pensions.

Equality Challange Unit. (2014) Supporting disabled students' transitions from higher education into employment: what works? London: Equality Challange Unit.

Foster D. (2015) Devolution and disabled workers: the experiences of union equality representatives in Wales. Industrial Relations Journal 46: 153-168.

Foster D and Fosh P. (2010) Negotiating 'difference': representing disabled employees in the British workplace. British Journal of Industrial Relations 38: 560-582.

Freeman R. (2005) Fighting for other folks' wages: the logic and illogic of living wage campaigns. Industrial Relations 44: 14-31.

Frege, C, Heery E and Turner L (2004), The new solidarity? Trade union coalition-building in five countries', in C. Frege and J. Kelly (eds), Varieties of Unionism: Strategies for Union Revitalization in a Globalizing Economy. Oxford, Oxford University Press pp. 137-158.

Gusdorf G. (1980) Conditions and limits of autobiography. In: Olney J (ed) Autobiography Essays Theoretical and Critical. Princeton, NJ: Princeton University Press.

Harding C, Ghezelayagh S, Busby A, et al. (2014) Findings from the Survey of Employment Tribunal Applications 2013. London: Business Innovation and Skills.

Heery E. (2006) Equality bargaining: where, who, why? Gender, Work \& Organization 13: $522-543$

Heery E and Frege C. (2006) New Actors in Industrial Relations. British Journal of Industrial Relations 44: 00007-01080.

Heery E, Healy G and Taylor P. (2004) Representation at Work: Themes and Issues, London: Palgrave.

Heery E, Williams S and Abbott B. (2012) Civil society organizations and trade unions: cooperation, conflict, indifference. Work, employment and society 26: 145-160. 
Hickey R. (2012) End-users, Public Services, and Industrial Relations: The Restructuring of Social Services in Ontario. 67: 590-611.

Hood C, Rothstein H and Baldwin R. (2001) The Government of Risk: Understanding Risk Regulation Regimes, Oxford: Oxford University Press.

Hopkins B and Dawson C. (2016) Migrant workers and involuntary non-permanent jobs: agencies as new IR actors? Industrial Relations Journal 47: 163-180.

Hoque K and Noon M. (2004) Equal opportunities policy and practice in Britain: evaluating the 'empty shell' hypothesis. Work, Employment \& Society 18: 481-506.

Humphrey JC. (2000) Researching disability politics, or, some problems with the social model in practice. Disability \& Society 15: 63-86.

Kirton G and Greene A-M. (2015) The Dynamics of Managing Diversity: A Critical Approach. Fourth Edition, London: Routledge.

Kolins Givan R. (2007) Side by side we battle onward? Representing workers in contemporary America. British Journal of Industrial Relations 45: 0007-1080.

Lengnick-Hall M, Gaunt P and Kulkarni M. (2008) Overlooked and underutilized : people with disabilities are an untapped human resource. Human Resource Management Journal 47: 255-273.

Milner S. (2017) Trade unions, equality and diversity: an inconsistent record of transformative action. Work, Employment \& Society 31: 191-196.

Milner S and Gregory A. (2014) Gender equality bargaining in France and the UK: An uphill struggle? Journal of Industrial Relations 56: 246-263.

Mustchin S (2014) Union modernisation, coalitions and vulnerable work in the construction sector in Britain. Industrial Relations Journal 45 121-136

Office for Disability Issues. (2014) Disability Fact and Figures. London: UK Government. ONS. (2017) Labour market status of disabled people. Available at:

https://www.ons.gov.uk/employmentandlabourmarket/peopleinwork/employmentandemploye etypes/datasets/labourmarketstatusofdisabledpeoplea08.

Osterman P. (2006) Community organizing and employee representation. British Journal of Industrial Relations 44: 629-649.

Piore M and Stafford S. (2006) Changing regimes of workplace governance: shifting axes of social mobilization and the challenges to industrial relations theory. Industrial Relations 45: 299-325.

Richards J and Sang K. (2016) Trade unions as employment facilitators for disabled employees. The International Journal of Human Resource Management 27: 1642-1661. 
Schur L, Kruse D, Blasi J, et al. (2009) Is Disability Disabling in All Workplaces? Workplace Disparities and Corporate Culture. Industrial Relations: A Journal of Economy and Society 48: $381-410$.

Tailby S, Pollert A, Warren S, et al. (2011) Under-funded and overwhelmed: the voluntary sector as worker representation in Britain's individualised industrial relations system.

Industrial Relations Journal 42: 273-292.

Tapia M. (2013) Marching to different tunes: commitment and culture as mobilizng mechanisms of trade unions and community organizations. British Journal of Industrial Relations 51: 0007-1080.

TUC (2015) Trade unions and disabled members: why the social model matters. TUC:

London

Van Wanrooy B, Bewley H, Bryson A, et al. (2013) The 2011 Workplace Employment Relations Study First Findings. Swindon: ESRC.

Williams S, Abbott B and Heery E. (2011a) Civil regulation and HRM: the impact of civil society organisations on the policies and practices of employers. Human Resource Management 21: 45-59.

Williams S, Abbott B and Heery E. (2011b) Non-union worker representation through civil society organisations: evidence from the United Kingdom. Industrial Relations Journal 42: 69-85.

Williams S, Heery E and Abbott B. (2010) Mediating equality at work through civil society organisations. Equality, Diversity and Inclusion: An International Journal 29: 627-638.

Wilton RD. (2006) Working at the margins: Disabled people and the growth of precarious employment. In: Pothier D and Devlin R (eds) Critical Disability Theory: Essays in Philosophy, Politics, Policy and Law. Vancouver: UBC Press, 129-150. 